Intervención (ISSN-2448-5934), enero-junio 2019, año 10, núm. 19: 36-50.

DOI: 10.30763/Intervencion.2019.19.207

Postulado/Submitted: 24.01.2018 - Aceptado/Accepted: 12.03.2018 - Publicado/Published: 06.05.2019

\title{
Albert A. Giesecke Parthymüeller y la conservación en el Templo Pintado: documentos inéditos
}

\section{en torno de la conservación en Pachacamac en 1938}

Albert A. Giesecke Parthymüeller and the Preservation of the Painted Temple: Unpublished Documents Regarding Preservation in Pachacamac in 1938

\author{
Gerbert Asencios Lindo \\ Facultad de Arquitectura Urbanismo y Artes, \\ Universidad Nacional de Ingeniería (UNI), Perú \\ gerbert.asencios@gmail.com
}

\section{Resumen}

El Templo Pintado es uno de los edificios más importantes del Santuario de Pachacamac, centro de peregrinación durante la época prehispánica. Si bien su conservación fue iniciada por Albert Antonhy Giesecke Parthymüeller en 1938, poco se conoce sobre los trabajos que realizó en el Templo Pintado. El presente texto de INVESTIGACIÓN expondrá, mediante la revisión de publicaciones y documentos inéditos del archivo de Albert Giesecke, las actividades que realizó durante su intervención en Pachacamac, relacionadas en cartas y escritos diversos. Así, los documentos que se ofrecen y analizan testifican una de las primeras labores de conservación de ese edificio, lo que permite construir la historia de la conservación en Pachacamac y de los monumentos arqueológicos en el Perú.

\section{Palabras clave}

Templo Pintado; Pachacamac; Albert Giesecke; conservación; pintura mural; Perú

Abstract

The Painted Temple is one of the most important buildings of the Sanctuary of Pachacamac, a center of pilgrimage during the pre-Hispanic era. Although its preservation was initiated by Albert Antonhy Giesecke Parthymüeller in 1938, little is known about the work he did in the Painted Temple. This RESEARCH will present, through the review of publications and unpublished documents from the archive of Albert Giesecke, the activities that he carried out during his intervention in Pachacamac, listed in various letters and writings. Thus, the documents offered 
and analyzed testify to one of the first preservation works of that building, which allows constructing the history of preservation in Pachacamac and other archaeological monuments in Peru.

\section{Keywords}

Painted Temple; Pachacamac; Albert Giesecke; Preservation; Murals; Peru

\section{Ubicación}

I Santuario Arqueológico de Pachacamac se ubica en la costa central del Perú, provincia y departamento de Lima, en la margen derecha del río Lurín. Cuenta con una superficie de 465 ha, un tercio de la cual está conformada por las edificaciones más importantes, en tanto que el resto queda pendiente de investigar. El santuario, que se encuentra a unos $600 \mathrm{~m}$ de la línea de playa del océano Pacífico (Pozzi-Escot 2018), representó un gran centro de peregrinación que estaba integrado a un sistema vial de camino conocido como el Qhapaq Ñan, donde Pachacamac destacó en el tramo hacia el asentamiento inca de Hatun Xauxa (Pozzi-Escot et al. 2013).

Julio C. Tello (2010) diferenció cuatro zonas dentro del santuario: 1. La de los templos al interior de la Primera Muralla, donde se hallan el Templo del Sol, el Templo Pintado materia del presente artículo, el Templo Viejo de Pachacamac y la zona de cementerios. 2. La de los grandes aposentos o palacios cercados, dispuestos en la parte central, entre la Primera y la Segunda Muralla, donde también se ubican los edificios conocidos como las Pirámides con Rampa. 3. La de los aposentos menores, aparentemente cercados y ubicados en el lado este del santuario. 4. La de los suburbios y residencias, ubicados en el lado norte, limitado por lo que se conoce como la Tercera Muralla (Figura 1).

Luego de la investigación de Uhle en el Santuario de Pachacamac a finales del siglo XIX, no se retomaron acciones sino hasta los últimos años de la década de 1930, con la intervención de Albert Giesecke, a tratarse en las siguientes líneas. Entre 1940 y 1944, Julio C. Tello intervino el santuario y realizó exploraciones preliminares en diversas zonas, y concluyó con la restauración a gran escala del Acllawasi, que estuvo orientado por los presupuestos teóricos de Viollet-le-Duc (Asencios 2017). A fines de los años cincuenta y principios de los sesenta: de 1957 a 1964, Arturo Jiménez Borja intervino diversos monumentos, como la Pirámide con Rampa 1 y la Calle Norte Sur; se sumó a su equipo de trabajo el arqueólogo Alberto Bueno y realizó la intervención del Templo del Sol, el Acllawasi, el Palacio de Taurichumpi y el Complejo de Adobitos, labores que, en 1969, interrumpió el entonces gobierno militar de Velazco Alvarado. En la

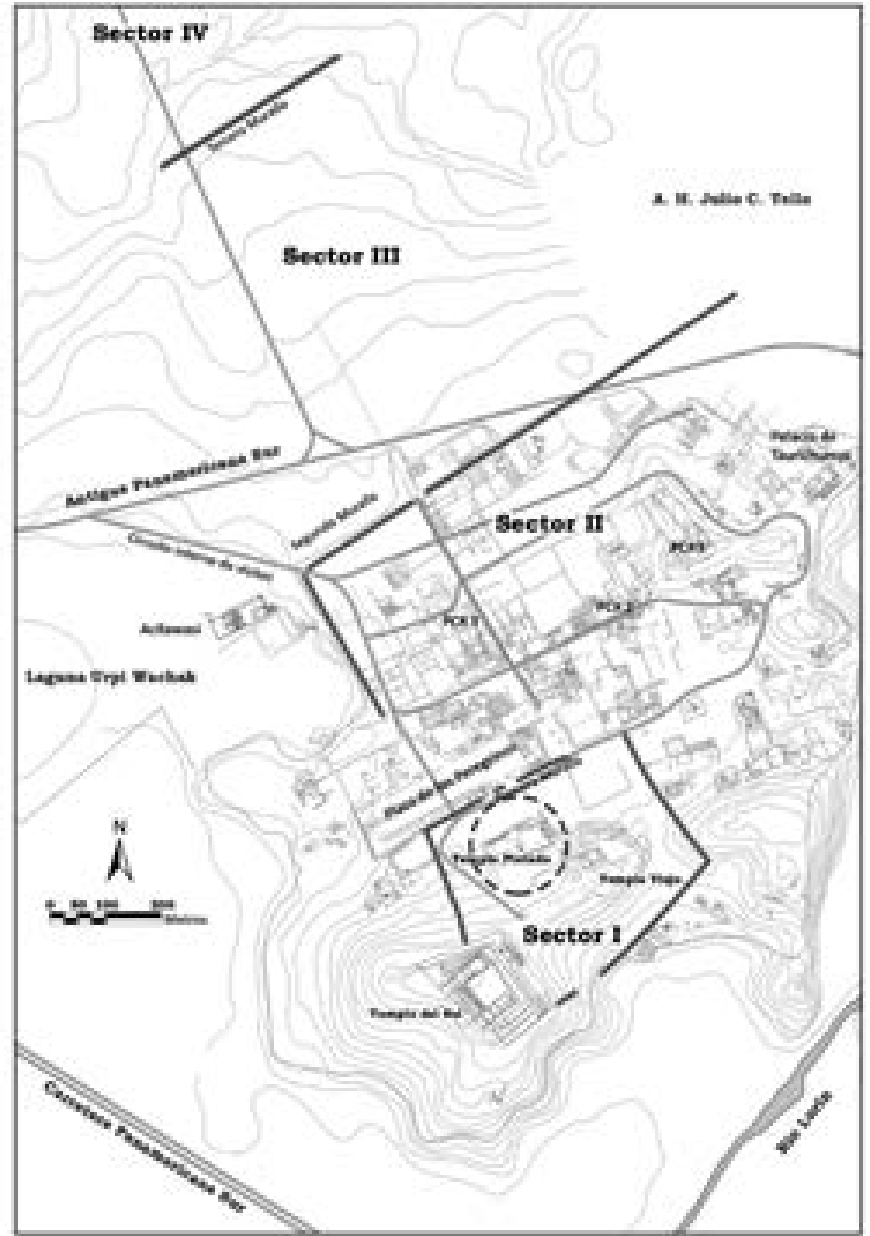

FIGURA 1. Plano del Santuario de Pachacamac, adecuado para la presente investigación (Fuente: Go Matsumoto, 2005: 55).

década de 1980, las labores de Régulo Franco y Ponciano Paredes centraron sus intervenciones en la Pirámide con Rampa 2, el Templo Pintado, el Templo Viejo y la Cuarta Muralla, actuaciones cuyos óptimos resultados significaron una aportación metodológica en la investigación arqueológica respecto de sus predecesores. En la década de 1990 se sumaron las investigaciones de Peter Eeckhout y Carlos Farfán, con el "Proyecto Ichma", enfocadas en la Pirámide con Rampa 3 y otros sitios ubicados en el santuario. En la primera década del siglo XXI, Izumi Shimada y el "Proyecto Pachacamac" realizó sus investigaciones en la Laguna y Templo de Urpi Wachaq, la Plaza de los Peregrinos y la Pampa Norte; paralelamente, Krzysztof Makoswki, con el "Proyecto Lomas de Lurín", intervino el acceso de la Segunda Muralla y la parte frontal de la Pirámide con Rampa 1. Finalmente, desde 2007 hasta la fecha, Denise Pozzi Escot y su equipo de trabajo han llevado una ardua y continua labor, cuyos resultados han sido materia de diversas publicaciones sobre ese importante santuario arqueológico.

El Templo Pintado fue el edificio dedicado al Dios de Pachacamac; es uno de los importantes monumentos del santuario y se ubica al interior de la Primera Muralla; 
presenta bases de construcción con "adobitos" del periodo Lima (200-600 d.C.) (Pozzi-Escot 2018). Según Pacheco (2014), el templo fue construido por los Yshma (900-1300 d.C.) y se caracterizó por presentar pinturas murales a manera de gradas escalonadas y dispuestas en paneles con fondo rojo y amarillo, sobre el que se inscribieron diseños de peces, aves, plantas y figuras humanas (Pozzi-Escot et al. 2013; Pacheco 2014; Marcone 2003), los cuales se ubicaban en el frontis norte del referido edificio (Figuras 2 y 3 ).

El monumento cuenta con una superficie aproximada de $9500 \mathrm{~m}^{2}$ y una altura de alrededor de $5 \mathrm{~m}$. Para PozziEscot et al. (2013), esas pinturas murales tenían gran importancia y jerarquía religiosas; así, el Templo Pintado trascendía simbólicamente por medio de sus imágenes e impactaba a los peregrinos desde la entrada al santuario. En la actualidad, el monumento conserva $42 \mathrm{~m}^{2}$ de pintura mural —de aproximadamente $400 \mathrm{~m}^{2}$ - de fachada del monumento.

\section{Albert Giesecke, una breve biografía}

Antes de adentrarnos en las labores de conservación en el Santuario de Pachacamac, es oportuno acercarse brevemente a la biografía de Albert Giesecke, cuya actuación en la historia peruana fue trascendental como servidor público en la gestión escolar, universitaria y municipal, en la promoción del turismo y, primordialmente, en el campo arqueológico. La obra de Marcial Rubio Correa (2007) titulada "Albert Anthony Giesecke Parthymüeller. El más peruano de los norteamericanos", relata los más importantes episodios de su vida, en la que menciona anécdotas, algunas de las cuales se describirán en las siguientes líneas; invito al lector a revisar esa publicación (Figura 4).

Giesecke nació en Pensilvania, Estados Unidos, en 1883 y falleció en Lima en 1968. Sus padres, de origen alemán, fueron Albert Frederick Giesecke y Catherine Parthymüeller. Cursó estudios primarios en el colegio público de West Philadelphia, donde destacó académicamente. Los estudios secundarios los llevó a cabo en el Central High School of Philadelphia. Cursó estudios universitarios de economía y ciencias políticas en la Universidad de Pensilvania; posteriormente se matriculó en la Universidad de Lausanne, Suiza, y cursó las materias de ciencias sociales; sin embargo, su estadía fue corta y regresó a Estados Unidos por razones de trabajo y estudios, donde obtuvo el grado de doctor en la Universidad de Cornell. También cursó materias en el Carnegie Institute, en el que se especializó en temas de asuntos comerciales (Matos Mar et al. 1981).

Llegó a Perú en 1909, motivado por un contrato laboral como docente en la Universidad Nacional Mayor de San Marcos y el Colegio Nuestra Señora de Guadalupe, que no concretó debido a su designación como rector de la Universidad San Antonio Abad en Cusco, desde 1910

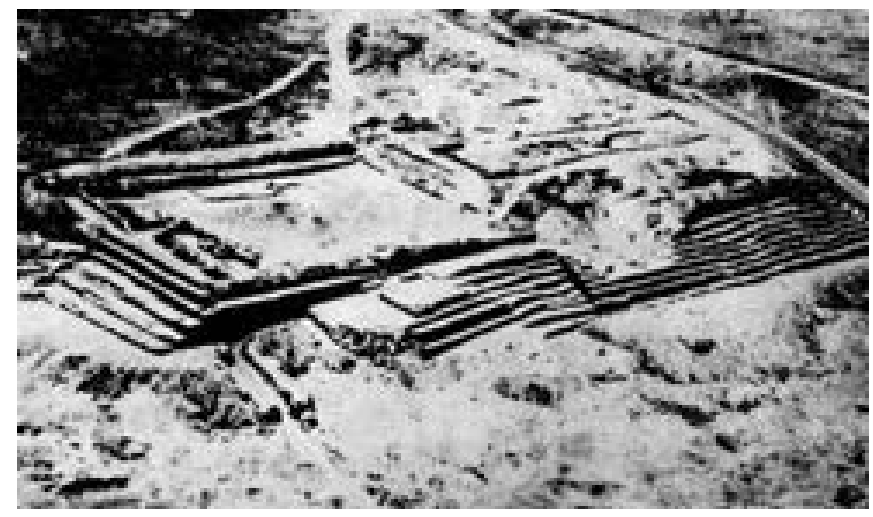

FIGURA 2. Toma aérea del Templo Pintado en Pachacamac tras las labores de conservación (Fuente: Muelle y Wells 1939: Figura 2).

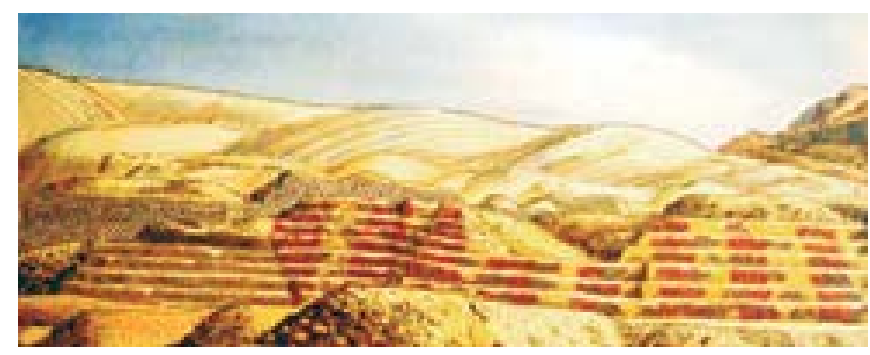

FIGURA 3. Boceto de cómo se veían las gradas escalonadas de pintura mural en el Templo Pintado (Fuente: Pacheco 2014: 151 [Archivo Tello 1940]).

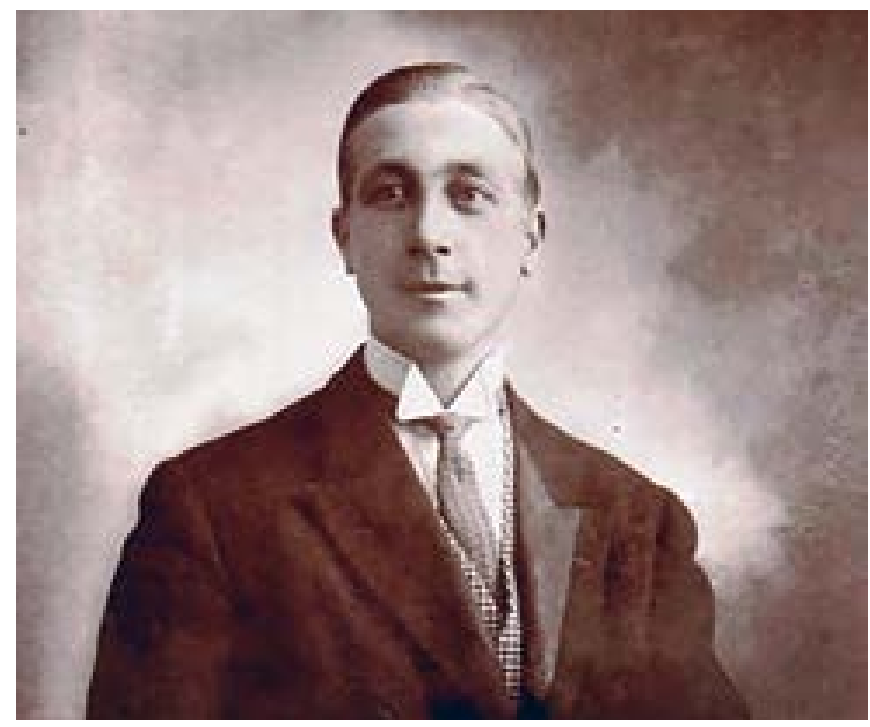

FIGURA 4. Albert Anthony Giesecke Parthymüeller (Fuente: Rubio Correa 2007: 100).

hasta 1923, por el presidente Augusto Bernardino Leguía. Ahí emprendió una importante labor por la educación universitaria para mujeres, la inclusión de actividades deportivas, la adquisición de un museo arqueológico y la incorporación de estudios antropológicos y etnológicos en las carreras que se impartían en el claustro universitario.

Fue electo presidente del Centro Geográfico del Cusco en 1912 y llevó a cabo el primer censo de la ciudad (Matos Mar et al. 1981). Ejerció el cargo de regidor y 
alcalde municipal desde 1913, cuando destacaron obras ediles como el alcantarillado de la urbe y la construcción de la pista de la Plaza de Armas a la Fortaleza de Sacsahuamán. Durante el segundo gobierno de Leguía, fue director general de Educación, cuya gestión fue reconocida en la moralización de los nombramientos de docentes.

Según Rubio Correa (2007), su interés por la arqueología se evidenció durante su vida universitaria, cuando tomó cursos relacionados con la materia y visitó museos en su país y Europa. Como rector, favoreció los estudios arqueológicos en la zona, con la organización de excursiones a lugares históricos. Luis Eduardo Valcárcel (Matos Mar et al. 1981) relata que, como estudiante y dirigido por Giesecke, investigó las ruinas incaicas en un momento en que muy poco se conocía sobre ellas.

Como miembro de la Sociedad de Historia del Cusco, cumplió una labor fiscalizadora ante a hechos de afectación contra monumentos arqueológicos y participó en actividades que aportaron al conocimiento arqueológico: así, en 1940, con el apoyo de la Fundación Wenner Green, dio a conocer sitios arqueológicos cercanos a Machupicchu, denominados Phuyupatamarca y Sayacmarca. Igualmente, contó con la confianza de Leguía para la obtención de las colecciones arqueológicas pertenecientes a José Lucas Caparó Muñiz, Víctor Larco Herrera y Enrique Brüning.

\section{Contexto y problemática de la conservación en el Santuario de Pachacamac en 1938. Hallazgos en los documentos inéditos}

En 1938, todavía como funcionario de la embajada de los Estados Unidos, labor que cumplió hasta su retiro, Albert Giesecke recibió la encomienda de realizar la conservación del Santuario de Pachacamac, por motivo de la VIII Conferencia Internacional Americana con sede en Lima (Rubio Correa 2007).

Esa conferencia se llevó a cabo durante el gobierno de Óscar R. Benavides, quien solicitó al ministro de Relaciones Exteriores, el canciller Carlos Concha Cárdenas, preparar un programa de atenciones y visitas para las delegaciones participantes de ese acto internacional. En junio de 1938, éste le comunicó a Albert Giesecke Parthymüeller, funcionario de la embajada de Estados Unidos en Perú por aquel entonces, sobre la intención del Estado peruano para con sus anfitriones en dicha reunión, requiriéndole la elaboración, con detalle de tiempo y costos, de un plan de trabajo con el fin de que lo aprobara el presidente de la República (Rubio Correa 2007). Eso implicó la realización de un programa de visitas, inicialmente, a tres sitios arqueológicos: Pachacamac, Cajamarquilla y Chan Chan, con lo que se intervinieron los dos primeros, pues en Chan Chan no se ejecutarían labores de conservación sino hasta 1966, cuando el Patronato de Arqueología de Trujillo le encomendó a Francisco Iriarte Brenner realizar excavaciones y labores de limpieza y restauración en los palacios Tshudi, Arcoíris y Esmeralda (Ministerio de Cultura 2015).

Las actividades de Albert Giesecke en el Santuario de Pachacamac estuvieron focalizadas en los monumentos del Acllawasi, el Templo Pintado, el Templo del Sol y la construcción de un circuito de visitas (Rubio Correa 2007).

Sobre la conservación del Templo Pitado, Denise Pozzi-Escot et al. (2013) y Pacheco (2014) afirman que una de las problemáticas en su estudio es la ausencia de información de las actividades realizadas en 1938; investigaciones posteriores refieren, por su parte, los estudios de las pinturas murales y materiales empleados por Jorge Muelle y Robert Wells en 1939, las labores de excavación de Ponciano Paredes en 1983 y el trabajo sobre iconografía de las pinturas murales de Giancarlo Marcone en 2003. Precisan, además, que luego de la exposición de las pinturas murales en 1938, éstas fueron afectadas por la intemperie, los movimientos símicos y la actividad antrópica, que en conjunto generaron daños, como los desprendimientos, los colapsos y los graffitis, respectivamente. Ante ese escenario, Denise Pozzi-Escot et al. (2013) y Pacheco (2014) describen que tuvieron que establecer las directrices de trabajo que guiaran la ejecución de una serie de actividades con el fin de llevar adelante la adecuada intervención del monumento, las que consistieron en elaborar tanto un levantamiento topográfico y planimétrico del edificio como el registro de las pinturas murales y sus colores, la identificación de lesiones, la realización de pruebas arqueométricas, el seguimiento de las condiciones ambientales, el reconocimiento de su estratigrafía y la identificación de los momentos pictóricos. Seguidamente, se realizaron las labores de conservación: limpieza, consolidación de estructuras y de acabados, protección de enlucidos así como las posteriores tareas de monitoreo (Pozzi-Escot et al. 2013; Pacheco 2014).

A esa problemática, los documentos que alberga el archivo Albert Giesecke, ubicados en el Instituto Riva Agüero (IRA) de la Pontificia Universidad Católica del Perú (PUCP), documentan la intervención del Templo Pintado, labor que fuera ejecutada entre agosto y diciembre de 1938 (Rubio Correa 2007), la que se compone de escritos que brindan información fundamental y necesaria que permitirán conocer la planificación, la metodología y los procedimientos técnicos llevados a cabo para la conservación de dicho monumento arqueológico.

\section{Documentos relacionados con la planificación de la intervención}

Marcial Rubio Correa (2007) relata que Albert Giesecke elaboró, con su respectivo presupuesto, un plan de trabajo que le permitiera intervenir mediante acciones de lim- 
pieza el Templo del Sol, el Templo Pintado y el Acllawasi, además de consturir un circuito de visitas, como se ha descrito líneas arriba.

Vale comentar que, como funcionario público durante el gobierno de Augusto B. Leguía (1919-1930), Giesecke redactaba borradores de decreto de ley para el presidente. ${ }^{1}$ Con la misma dinámica de trabajo, proyectó con el presidente Óscar R. Benavides dichos documentos que promovían la conservación del Santuario de Pachacamac y Cajamarquilla, aunque no fueron aprobados ni publicados; pese a ello, el tomar conocimiento de éstos permite conocer su propuesta de trabajo sobre la tarea encomendada. Así, tales proyectos de ley justificaban la intervención en Pachacamac y postulaban la conformación de un equipo de trabajo, como se describe a continuación:

Que los monumentos arqueológicos constituyen una riqueza nacional cuya conservación se impone;

Que ellos representan una fuente de estudio histórico y científico; que reiterados informes de las autoridades encargadas de su supervigilancia y conservación demuestran que el Estado debe adoptar medidas eficaces si desea evitar que desaparezcan dichos monumentos;

Siendo conveniente iniciar en el día, las labores de conservación de los monumentos que existen diseminados cerca de Lima y Trujillo a fin de que a la vez podrán conocerlo mejor las Delegaciones a la VIII Conferencia Panamericana, y los delegados al Congreso Internacional de Americanistas, próximamente a reunirse acá.

Por tanto etc.

Ha venido a expedir la siguiente ley:

Artículo 1. El Ministerio de Relaciones Exteriores asumirá por ahora la supervigilancia y las labores inherentes a la conservación de los monumentos arqueológicos de Pachacamac, Cajamarquilla, Chan-Chán.

Artículo 2. El Ministerio de Relaciones Exteriores constituirá un Comité Consultivo para los fines que se contrae en el artículo anterior, dictará las medidas, que sean necesarias para que se lleve a cabo la conservación de los monumentos citados en esta ley.

Artículo 3. Los Ministros de Fomento y Guerra facilitarán al Ministerio de Relaciones Exteriores al personal y elementos materiales que sean menester para los fines a que se contrae esta ley.

Artículo [4]. Los gastos que ocasione esta ley se cargarán a la cuenta de... denominado..." (Giesecke ca. 1938, AG-D-195).

Asimismo, se elaboró el borrador del decreto que reglamentaba la constitución del comité consultivo y sus integrantes:

1 Estos documentos luego eran aprobados y firmados por Augusto B. Leguía; mediante ese mecanismo se obtuvieron las Colecciones de Víctor Larco Herrera y Enrique Brüning así como otras actividades cuando ocupó el cargo de director general de Educación (Rubio Correa 2007).
En cumplimiento del artículo 2 de la ley número... del... de... de 1938, y estando lo acordado;

Se resuelve:

Artículo 1. Desígnese para constituir al Comité Consultivo a los señores Julio C. Tello, Luis E. Valcárcel, Alberto A. Giesecke, y Pedro Villar Córdova.

Artículo 2. Las atribuciones del Comité Consultivo serán las que fija el reglamento que se ha aprobado en esta fecha.

$$
\text { R y C }
$$

En conformidad con la ley número... y la resolución... suprema de... se expide... el siguiente Reglamento de las atribuciones del Comité Consultivo.

Artículo 1. El Comité Consultivo se compone de cuatro miembros, además del Ministro de Relaciones Exteriores, quien lo presidirá.

Artículo 2. Son atribuciones del Comité Consultivo:

a) Informar sobre las materias que su presidente se somete a su conocimiento.

b) Decidir en cuanto a la forma más práctica y rápida para que se lleve a cabo, dentro de los monumentos arqueológicos existentes en las cercanías de Lima mencionados en la ley número...

c) Formular (y aprobar) el presupuesto para cada uno de los monumentos que se han de conservar.

Artículo 3. Tres miembros constituyen quórums para sesionar. Los acuerdos se tomarán por mayoría de votos. Se llevará un libro de actas de las sesiones. El presidente del Comité citará a sesión. El Comité no manejará los fondos, siendo esta función de la incumbencia del (Contador del Min. de R. Ex.) (Giesecke ca. 1938, AG-D-195).

Constituido el grupo de trabajo, Giesecke puso énfasis en la necesidad de formular un plan de actividades que orientara sus intervenciones, como se evidencia en el documento titulado Memorando:

Trabajo en Pachacamac: El plan de trabajo de Pachacamac sería demasiado costoso si se realizase una obra completa. Lo de Sacsahuamán y Pisac en el Cuzco en 1933-34 costó más de cien mil soles. A fin de poder realizar las obras con verdadera economía, conviene que una buena parte se haga utilizando los servicios del Batallón de Zapadores \#2, así como materiales y herramientas de trabajo que posee dicho Batallón. Solamente de esta manera se podrán realizar estos trabajos de conservación dentro del plazo señalado y a un gasto relativamente módico.

Se requiere para realización de otros en Pachacamac:

- Un maestro albañil y varios albañiles ayudantes, para calzar los cimientos de los muros, y tapar los huecos con adobe o barro sin desfigurar los muros.

- Cantidad suficiente de herramientas: picos, palas, carretillas, barrenos, madera, martillos, badilejos, sogas, etc.

- Albergue para tantos operarios - quien sabe carpas prestadas del Ejército-. Transportar diariamente los operarios sería costoso y con mucha pérdida de tiempo entre 
Lima y Pachacamac. Preferible sería facilitarles carpas y comida en el mismo sitio de Pachacamac.

- El Ministerio de Fomento debe encargarse directamente de componer los caminos, para cuyo fin pondrían su material y personal idóneo.

- Un requisito indispensable será que un empleado destacado del Museo Nacional esté permanentemente en el sitio de las obras, a fin de asegurar los aspectos arqueológicos y también para que reciba y catalogue el material de valor arqueológico que pudiera encontrarse durante esta obra de conservación de Pachacamac. Este material sería para el Museo Nacional.

- Una cámara fotográfica para tomar las vistas antes de iniciar una obra de conservación; vistas del trabajo que se realizan; y vistas de la obra concluida. Este archivo es esencial.

- Un carro esencial para movilidad para los que inspeccionen o supervigilen las obras de conservación.

[...]

En general todos los sitios mencionados, es el Ministerio de Fomento que podrá encargarse directamente de compostura y mejora de los caminos de acceso a los monumentos materia de este Memorandum. No se requiere camino de asfalto ni nada parecido; a los caminos actuales de tierra se les puede agregar un poco de ripio, después de su nivelación, y si cabe, incluir una capa de petróleo o sustancia análoga, que sea fácil y rápidamente aplicable.

Todo lo concerniente a pagos y cuentas debe controlarse por la contaduría del Ministerio, mediante un empleado especial en dicha Contaduría.

[Giesecke ca. 1938, AG-D-194].

Otro documento hallado en dicho archivo describe las actividades en el Templo Pintado:

Completar la grada que estaba por terminarse, y echar tierra en chaflán contra la cara interior para sostener dichas gradas mejor. Colocar mampara de vidrio en los sitios indicados a Nervi (asegurarlas de lo mejor posible), Pinturas nichos y dibujos (Gonzalo lo hará), Señales: postes deben colocarse en los sitios que yo indique [Giesecke ca. 1938, AG-D-0221].

Asimismo, un documento más, titulado Memorando, describe la necesidad impostergable de la intervención:

Si es verdad que toda labor de conservación debe hacerse bajo la inmediata supervigilancia de técnicos, con métodos y de acuerdo con un plan general, a fin de no dañar el material arqueológico que existe en estos monumentos es también muy cierto que al no iniciar cuanto antes una labor aunque fuese preliminar y solo parcial, de conservación, tendrán estos monumentos que desaparecer y en su consecuencia perderse todo este conjunto de material para la reconstrucción de la historia de la patria [...] [Giesecke ca. 1938, AG-D-0221].

\section{Documentos requiriendo opiniones} y recomendaciones de intervención

Durante la planificación de las actividades, Giesecke remitió una serie de cartas a científicos en las que solicitó sus opiniones, como la del científico peruano Santiago Antúnez de Mayolo, ${ }^{2}$ manifestándole: "Apreciado amigo: Estimaré mucho tener su opinión en cuanto a la labor de limpieza y conservación en las ruinas de Pachacamac que estoy realizando por encargo del Gobierno. Le saludo cordialmente su afmo. y amigo S. S." (Giesecke 1938c, Giesecke para Antúnez de Mayolo, 21 de octubre de 1938).

De igual modo, consultó la opinión del padre Pedro Villar Córdova, investigador arqueológico del valle de Lima, a quien le escribió:

Apreciado amigo:

Sabedor de que ha visitado $U d$. recientemente las ruinas de Pachacamac, me quedaré muy agradecido por su opinión en cuanto a la obras de limpieza y conservación que estoy realizando en dicho sitio en la actualidad. Igualmente, estimaré su idea en cuanto al uso a que se han destinado las ventanillas del cuarto que se han limpiado en estos últimos días.

Le saluda cordialmente su afmo. y amigo y S. S.

[Giesecke 1938, Giesecke para Villar Córdova, 14 de octubre de 1938].

Giesecke se coordinó con Luis E. Valcárcel, a quien solicitó indicaciones para la ejecución de las labores de conservación:

A fin de conservar en la mejor forma posible las gradas del Templo de Pachacamac que se han puesto a la vista con motivo de la obras de limpieza que el Gobierno está realizando, solicito que me indique, cuál, en su opinión, es la manera más eficaz para asegurar conservación de la dichas gradas en la mejor forma posible [Giesecke 1938d, Giesecke para Valcárcel, 21 de octubre de 1938].

También mantuvo comunicación con Wendell Bennett, destacado arqueólogo estadounidense, en el que le informa sobre los hallazgos en Pachacamac y le solicita recomendaciones para su intervención:

[...] En el Templo de Pachacamac, en las escaleras y sobre los muros, hemos encontrado muchas pinturas de peces, plantas (¿maíz?), partes de seres humanos en muchos colores: rojo, negro, amarillo, naranja, azul. Algunos peces están de pie en su cola, otros en diferentes formas con la boca abierta o cerrada, las aletas arriba o abajo, etc.

\footnotetext{
${ }^{2}$ Descubridor del neutrón y conocido por sus proyectos de las centrales hidroeléctricas, quien realizó interpretaciones sobre la iconografía del lanzón y el obelisco Tello en Chavín de Huántar (Sotelo 1987).
} 
El problema que encuentro difícil de resolver ahora es la preservación de estas pinturas, que en muchos casos están completamente destruidas, debido al material caído hace siglos sobre la pintura. ¿Qué hizo el Instituto Carnegie u otras instituciones en circunstancias análogas como en México y Centroamerica? Por favor, hágame saber por correo aéreo de retorno, junto con el lugar donde se pueden conseguir los materiales, el precio y el mayor detalle posible que me pueda brindar sobre el método de aplicación [Giesecke 1938a, Giesecke para Bennett, 14 de septiembre de 1938].

La respuesta de Bennett no se hizo esperar: remitió la siguiente:

Su carta que habla acerca de los importantes descubrimientos en Pachacamac acaba de llegar y es muy asombroso. Estoy enviando su carta a Paul Richards del Museo Americano, quien está técnicamente capacitado para responder las preguntas sobre preservación: estoy solicitando al Sr. Richards, enviar la información por correo aéreo [Bennett 1938, Bennett para Giesecke, 20 de septiembre de 1938].

Seguidamente, Paul Richards, del Museo Americano de Historia Natural de Nueva York, remitió un correo a Giesecke y recomendó lo siguiente:

El Dr. Bennett me ha referido su carta y considero que es extremadamente difícil recomendar medidas de protección de un mural sin conocer su composición y la condición en que se encuentra. Sin embargo, asumo que se trata de un tipo de fresco en mal estado de conservación.

Primero recomendaría que usted complete las fotografías y bocetos a color de todo el fresco antes de realizar cualquier restauración. Segundo, se le debe proteger bien de los elementos, y debe ser cuidadosamente limpiado con brochas suaves (pelo de camello o marta). Donde sea posible, como en grietas, agujeros o a lo largo de los bordes, verter un solución diluida de Ambroid, un poco a la vez, dejando que fije, y repitiendo luego hasta que la absorción esté completa. Esto asegurará una unión firme entre el fresco y su soporte. Una vez que todas las grietas y bordes hayan sido lentamente saturados, se puede rociar una mezcla muy líquida de acetona y Ambroid usando un soplador de boca para aplicar fijativos o puede ser cepillado con un fino pincel de pelo de camello. Cada aplicación debe ser muy liviana, dejando tiempo suficiente para que se fije, y se deben hacer subsecuentes aplicaciones hasta que se forme un brillo muy fino apenas perceptible sobre la superficie.

Otras medidas de protección que se deberían tomar lo antes posible, podrían ser la cobertura con vidrios, la prevención de contacto con el exceso de humedad, eliminación de la luz directa del sol, etcétera.

El solvente o tíner y el cemento líquido incoloro Ambroid se puede comprar en Ambroid Company, Brooklyn, Nueva York.
Una parte del Ambroid con quince partes de solvente es una buena solución para llenar las grietas y soportes. Una solución más líquida (una parte Ambroid con veinte o más partes de disolvente) es buena para rociar las superficies [Richards, 1938, Richards para Giesecke, 27 de septiembre de 1938].

En respuesta y señal de agradecimiento Giesecke escribió la siguiente misiva:

Reconozco con inmensa gratitud y aprecio su amable carta del 27 de septiembre con los datos concernientes a la conservación de los frescos en colores que se encuentran en las gradas del Templo de Pachacamac, los cuales fueron recientemente descubiertos durante el proceso de limpieza y preservación de esta antigua ruina cerca de Lima, solicité al Gobierno que obtenga de inmediato el cemento líquido Ambroid de la dirección que me proporcionó y confío en que llegue en avión durante el transcurso de la presente semana [Giesecke 1938, Giesecke para Richards, 17 de octubre de 1938].

Paralelamente, Albert Giesecke le escribió a Alfred Kidder, experto estadounidense en arqueología y conservación del Museo Peabody de Arqueología y Etnología de la Universidad de Harvard, ${ }^{3}$ al cual le pidió sugerencias para la adecuada intervención del Templo Pintado:

[...] Le escribo pidiéndole que me haga el favor de avisar por correo aéreo sobre el procedimiento utilizado por el Instituto Carnegie y otros organismos en la preservación de las pinturas en color que se han encontrado en América Central. Si [aquí] no se aplica rápidamente algún tipo de conservante, la intemperie y la mano del hombre las destruirá. ¿Dónde se puede obtener el material? Su costo; método de aplicación, etc. (se desea información) [Giesecke 1938, Giesecke para Kidder, 20 de setiembre de 1938].

Kidder respondió inmediatamente con la siguiente carta:

[...] Su trabajo en Pachacamac suena muy interesante. En Centroamérica el Instituto Carnegie de Washington ha tenido algo de éxito en la preservación de la pintura mural amenazada por la humedad que hace que se desprendan las capas de yeso sobre las que se aplican los frescos. Intentos sobre pintura que sí se ha preservado se han limitado a su registro y tapado.

Ud. tiene dos opciones:

Remover [estrapar] la pintura, lo cual implica una complicada y costosa fórmula y mucha experimentación. Este método ha sido usado en Arizona, pero hasta ahora aquí nadie lo ha utilizado lo suficiente como para saber cuáles serán los resultados.

\footnotetext{
${ }^{3}$ Estudioso en temas arqueológicos de Pecos en Nuevo México, Arizona entre otros, y asesor del Instituto Carnegie de Washington para la intervención e investigación en Mesoamérica (Willey 1967).
} 
Probablemente se puede lograr preservar las pinturas [in situ] usando una resina sintética aplicada sobre una solución de acetona. Este método se debe usar sólo [cuando] las paredes, superficies y todo el interior estén totalmente secos. La mejor preparación se llama Alvar 770 (viscosidad). Quizá no lo pueda conseguir en Lima pero se vende en Shawinigan Product Corporation; Empire State Building, Nueva York, Nueva York. Cuesta unos 91 centavos por libra y 10 libras deberían ser suficientes. Si hay un sobrante, será muy útil [como insumo en las tareas del] museo. El solvente puede ser un acetato de amilo, mejor aún, acetona, probablemente disponible localmente ya que cualquier compañía química que produzca ácido sulfúrico debería tenerla a mano. Si no hay en Lima, lo puede obtener en Panamá, o de las siguientes empresas en los Estados Unidos: Mallinckrodt Chemical Works, 72 Gold Street, Nueva York, N. Y.; Merck and Company, Rahway, Nueva Jersey; The General Chemical Company, 40 Rector Street, Nueva York, N. Y. Se sugieren estas compañías [para pedidos en] cantidades pequeñas, pero si se pide un cilindro (que puede ser más barato en proporción si se tiene que importar la acetona), haga el pedido a Union Carbide Company, Nueva York, Nueva York.

Para preparar la solución, lo mejor es usar un mezclador mecánico similar al batidor de huevo. Una solución al 5\% (por peso o volumen) debería ser lo mejor para sus propósitos. Tendrá que experimentar en áreas pequeñas [del fresco] para determinar el mejor método de aplicación. Si la pared es lo suficientemente resistente, una buena opción sería usar una brocha mediana y de fibras firmes o, si la pared es muy delicada y la solución lo suficientemente líquida, se puede usar un espray. Después de la aplicación de una solución muy delgada como primera capa, se puede aplicar una solución ligeramente más espesa a manera de protección adicional. Si la atmósfera está muy húmeda, es posible que este método no funcione. El Alvar se puede poner blanco y tendrá que tomar una decisión sobre este experimento. Si el experimento funciona y el alvar no se vuelve blanco en un inicio, puede ser que sí lo haga luego, cuando la garua se intensifique. Pero si la pared estaba completamente seca [al momento de la aplicación], todo (el fresco y la solución para preservar) debería secarse con normalidad cuando la atmósfera pierda humedad. Otro experimento que podemos sugerir es probar aplicando en una pequeña área un buen barniz de espato (Valspar), prácticamente incoloro y diluido con trementina. Esto podría brindar un resultado más satisfactorio ya que es a prueba de agua y probablemente más fácil de conseguir y más barato que el alvar.

Los métodos aquí sugeridos son, de hecho, soluciones temporales. Las paredes tratadas de esta manera deberían permanecer en buenas condiciones durante algún tiempo, pero eventualmente se verán afectadas. Si desea remover [estrapar] la pintura, avíseme y le enviaré los detalles del proceso. Sin embargo, para fines de investigación realizar una reproducción precisa con la ayuda de una escala de colores como el Diccionario del color de Maertz y Paul of
Color, que creo que tienen en la biblioteca del Museo, es probablemente una opción más adecuada que arrancar las pinturas de su posición original [Kidder, 1938, Kidder para Giesecke, 20 de septiembre de 1938].

En atención a tales recomendaciones de Richards y Kidder como lo refiere Rubio Correa (2007), Giesecke tomó contacto con el Instituto Carnegie, ${ }^{4}$ que le envió materiales líquidos para conservación que debían aplicarse cada tres meses. Sin embargo, no hay descripciones de dicha aplicación.

\section{Documentos en relación con coordinaciones de intervención}

Cuando Giesecke obtuvo la resina que se aplicaría en el Templo Pintado, para coordinar la actividad le remitió a Luis E. Valcárcel una comunicación en el siguiente tenor: "Habiéndose Ud. ofrecido enviar al señor Muelle, del Museo para ver la mejor manera de aplicar una capa impermeable sobre los dibujos pintados en colores que se han hallado recientemente en las ruinas del Templo de Pachacamac. [...] Conviene que se realice esta labor a fin de evitar mayor deterioro de aquellos dibujos de color" (Giesecke 1938, Giesecke para Valcárcel, 3 de octubre de 1938).

De igual modo, Giesecke elaboró un memorando en el que informa sobre las labores realizadas y brinda sugerencias sobre lo que se tiene que hacer con el material asociado con el Templo Pintado.

1. Se han comprado materiales diversos a fin de realizar la limpieza y conservación de las ruinas de Pachacamac y Cajamarquilla [...]

2. Se ha encontrado una cantidad más grande y más importante del material arqueológico durante la limpieza de los escombros en Pachacamac del que se pensó al iniciar esta obra.

Es indispensableestudiar estematerial que está en el Museo Nacionaly publicar los resultados en la Revista del Museocon ilustraciones numerosas. El mundo arqueológico lo espera. Para dicho fin se requiere un subsidio especial. Este número de la revista podrá obsequiarse a las Delegaciones una vez impreso [...] [Giesecke ca. 1938, AG-D-0195].

\section{Documentos que informan acerca de los resultados de la intervención}

Finalmente, concluida la labor encomendada, Albert Giesecke remitió su informe a Carlos Concha Cárdenas, ministro de Relaciones Exteriores, en el que describía las actividades ejecutadas en el Templo Pintado.

\footnotetext{
${ }^{4}$ El Instituto Carnegie de Washington intervino en Centro América desde 1924 hasta 1954 en diversos e importantes monumentos como Chichén Itzá, Uaxactún (Schavelzon 1990).
} 
Trabajo en Pachacámac

Templo de Pachacámac

Se terminaron la limpieza de todas las gradas y de la plataforma encima de las gradas. Se encontraron muchos restos de material (retazos de cerámica [sic], telas, huesos, madera, etc.) y sobre todo momias de criaturas, llamas y cuyes. Todo este material ha sido remitido al Museo Nacional de Lima. Se hallaron gradas angostas especiales que subieron desde el cementerio hasta la plataforma de los cuartos del Templo. Se limpió las gradas que existen por el extremo este del Templo. Se encontró que algunas gradas estuvieron en tan mala condición que una obra formal de conservación que imponía en el día, y se procedió a realizar esa tarea. Una parte de las gradas faltó por completo, y se volvió a colocarla. En el sitio de conservación enorme ha existido hace mucho tiempo en el centro de las gradas del Templo, se ha vuelto a colocar dos gradas, rellenando parte de dicho sitio excavado. Se procedió así para la mejor conservación del resto de las gradas. Conviene completar esta obra, para la mayor solidez del Templo; al mismo tiempo debe utilizarse la tierra de desmonte proveniente de la antigua excavación, llevando la tierra nuevamente a su sitio tras de las gradas.

Delante del Templo del Pachacamac, al otro lado del cementerio existe una pequeña colina, Ilena de escombros y arena. Max Uhle llama a este sitio "la portería" del Templo de Pachacamac. Aunque no estaba dentro de mi plan de obras de limpieza y conservación en Pachacamac he creído necesario limpiar esta colina, a fin de que tenga un aspecto de parte de las ruinas y no meramente de una colina cualquiera natural. Al proceder a la limpieza encontré restos de muros pintados de rojo; un cuarto sumergido con restos de una ventana enlucida que mira hacia el Templo de Pachacamac; $y$, finalmente, gradas de piedra y a continuación un camino en chaflán que bajaba a una hilera de columnas que están en la pampa delante de "la portería".

Se procedió a aplicar una capa de cemento líquido a varios de los dibujos en colores (peces, plantas, aves) que se han encontrado en las gradas y paredes del Templo del Pachacamac. Se ha resuelto colocar un marco con vidrio delante de uno que otro de estos dibujos, y es de desear que puedan quedar ahí de manera permanente para la mejor conservación de estos dibujos en colores. Si se encuentra posteriormente un método mejor de conservación sería muy deseable aplicarlo cuanto antes [Rubio Correa 2007: 120-121].

Durante la ejecución de esas actividades de limpieza y conservación, se halló el ídolo de Pachacamac, cuya entrega, así como de otros elementos asociados (cerámica y textiles), se documentó y entregó al Museo Nacional de Lima (Figura 5); el contenido de la nota fue la siguiente: "Recibo por el siguiente material sacado del desmonte de las gradas del Templo Pachacamac: Un ídolo de madera de dos caras y $2 \frac{1}{2} 2$ metros de largo, y diámetro de $10-14 \mathrm{~cm}$ (Ídolo de Pachacamac)..." (Giesecke ca. 1938, AG-D-0194).

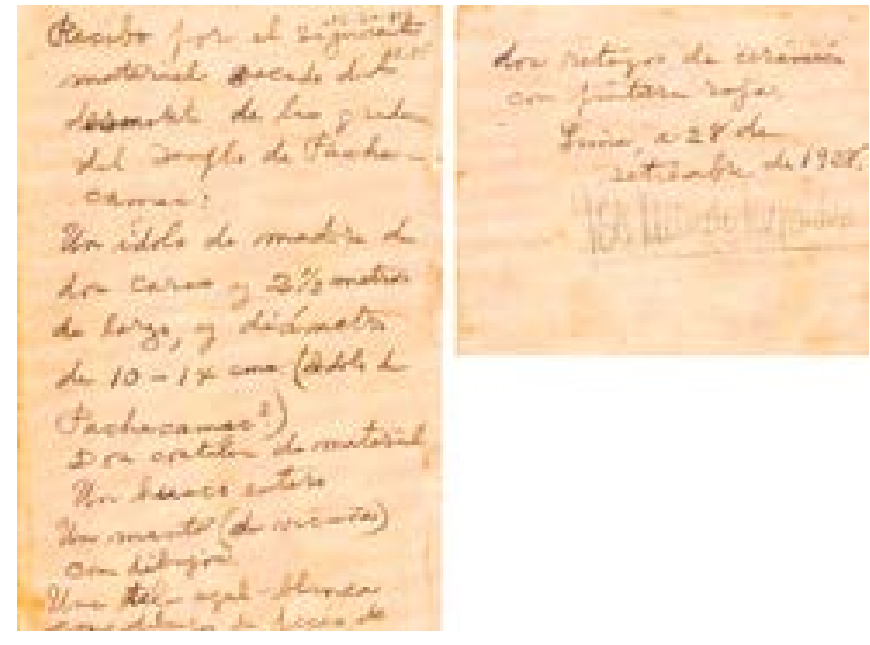

FIGURA 5. Nota de entrega al Museo Nacional del ídolo de Pachacamac y materiales asociados (Fuente: Archivo Albert Giesecke; Instituto Riva Agüero [AG-D-194], 2017).

\section{Análisis y discusión de la intervención en Pachacamac}

Con lo expuesto hasta el momento no sólo se conoce la importante participación de Albert Giesecke en la conservación en Pachacamac y, en especial, en el Templo Pintado, sino también, las actividades que se desprendieron de su accionar, aquellas que lamentablemente no se continuaron según sus indicaciones, generando consecuencias en el monumento décadas después, como han descrito Denise Pozzi-Escot et al. (2013) y Pacheco (2014).

Haciendo un análisis, la documentación expuesta reconstruye los siguientes escenarios en el que se ejecutaron los primeros trabajos de conservación en Pachacamac: el político, el teórico, el metodológico-técnico y el de gestión.

En el escenario político, como se ha dicho líneas arriba, se debió a la realización en Lima de la VIII Conferencia Internacional Americana, acto que se realizó durante el 9 y el 27 de diciembre de 1938 con la finalidad de:

[que]... las naciones de América, unidas por un ideal común, robustezcan los lazos tradicionales, y se esfuercen por crear nuevos vínculos solidarios que sirvan para protegerlas del peligro de la guerra entre ellas y para resguardarlas de toda amenaza de propagación a su suelos de conflictos extracontinentales [Arcila 2009].

En esa ocasión se elaboró un documento de pronunciamiento político, conocido como la Declaración de Lima o de Solidaridad de América, ${ }^{5}$ que suscribieron las

\footnotetext{
${ }^{5}$ El contenido de dicha declaración citaba: "En caso que la paz, seguridad o la integridad territorial de cualquier República americana sean amenazados por actos de cualquier naturaleza que puedan menoscabarla, tales actos son de interés común de toda América, y se hará efectiva la solidaridad coordinando sus respectivas voluntades soberanas mediante el procedimiento de consulta" (Villalta 2007: 69).
} 
20 naciones participantes. Por lo expuesto, este acto político internacional motivó la intervención en Pachacamac.

Analizando el marco teórico y normativo de conservación, durante la intervención de Pachacamac se encontraba vigente la Carta de Atenas (1931), documento internacional que representaba uno de los primeros hitos para la conservación del patrimonio cultural del siglo Xx: establecía las pautas técnicas de restauración y conservación de los bienes patrimoniales. José Hayakawa (2001) afirma que éste fue un documento elaborado por expertos en protección, conservación y restauración de monumentos, pero que no logró tener aceptación universal, como ocurrió con la carta del mismo título dada por el Congreso Internacional de Arquitectura Moderna $\left(\right.$ CIAM) ${ }^{6}$ en 1933. La carta de 1931 se centró sólo en la intervención y defensa de monumentos arquitectónicos de singular significación (Hayakawa 2001). Por su parte, Daniel Schavelzon (1990) precisó en relación con el reconocimiento de ese documento por los profesionales mexicanos de la época que, al no cuadrar con los principios de conservación establecidos basados en sus experiencias entre 1928 y 1932, pasó inadvertido para la actividad conservativa, no obstante que fue muy difundido entre los arquitectos, ingenieros y constructores, particularmente, en la Escuela de Arquitectura. Por lo expuesto, estamos ante un documento que, tras su aprobación y promulgación en 1931, fue medianamente reconocido en el Perú y México.

A esto se sumó, en el ámbito peruano, la carencia de experiencias previas de intervención en conservación de monumentos arqueológicos, en específico, sobre pinturas murales en arquitecturas en tierra, por lo que Albert Giesecke apeló a la experiencia de personalidades relacionadas con casos de la intervención de estucos, frescos y pintura murales en América del Centro y del Norte, con lo que obtuvo recomendaciones sobre técnicas y procedimientos para proceder con un plan de intervención, acorde con la época, referente al registro de la intervención y la limpieza del monumento (Figura 6), la integración de materiales y la consolidación de los murales pictóricos en el Templo Pintado. Además, procuró que dicha intervención no fuera reconstructiva, como se manifestó en el periódico La Prensa:

No se trata, agrega, de restaurar ni reconstruir las ruinas de Pachacamac o Cajamarquilla, tarea que queda reservada a profesionales más especializados y competentes que yo, sino de arreglar una y otra ruina, limpiándolas, diremos de escombros que dificultan su percepción objetiva de parte de los viajeros y facilitar el acceso a ellas. Como la obra que me ha encomendado el Ministerio es una contribución al renombre artístico y arqueológico del Perú he prestado mi concurso personal entusiasta y abnegado [Giesecke 1938b, 14 de septiembre: 3].

\footnotetext{
${ }^{6}$ Congreso Internacional de Arquitectura Moderna de 1933; en la Carta de Atenas se incluyen las funciones de las ciudades.
}

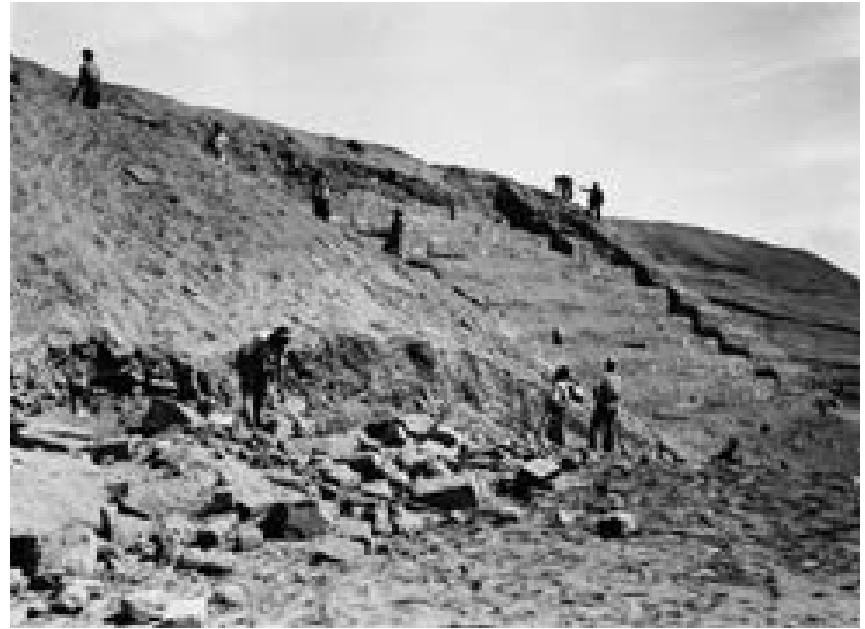

FIGURA 6. Limpieza de las gradas del Templo Pintado en 1938 (Fuente: Pozzi-Escot et al. 2013: 24).

Por otro lado, como consta en los borradores del decreto-ley, Giesecke sugirió la conformación de un comité consultivo que no se logró constituir. Éste debieron integrarlo reconocidas personalidades académicas en el estudio arqueológico e histórico, como Julio C. Tello, Pedro Villar Córdova, Luis E. Valcárcel, a quienes se sumó el propio Giesecke. Rubio Correa (2007) puntualiza que el presidente de la República, Benavides, quería que el trabajo se hiciera de manera rápida y eficiente, razón por la cual posiblemente prescindió de dicho comité y de las personalidades propuestas, como se expone en una anotación en la que Giesecke manifiesta:

Él está interesado en mejorar las ruinas de Cajamarquilla, Maranga y Chuquitanta. Aparentemente $[\ldots]$ no quiere encargar esta tarea a Valcárcel o Tello, quizá para evitar algunos asuntos [que puedan surgir] por diferencias profesionales; él mismo hace todos los arreglos y quiere que los Delegados vean aquel lugar, en lugar de que usen la mayor parte de su tiempo en recepciones, tés, etc. [Giesecke ca. 1938: AG-D-1261].

No es posible discernir a quién se refirió en dicho documento, pero, si se considera que Giesecke ejecutó su labor bajo la supervisión del Ministerio de Relaciones Exteriores, probablemente esa directiva provino del gobierno en turno. Por otro lado, Benavides le encargó a Julio C. Tello el proyecto del nuevo museo en Pueblo Libre con el fin de exhibir ahí los telares de Paracas para el referido acto internacional (Astuhuamán y Dagget 2005), pese a lo cual meses después el arqueólogo cuestionó la intervención en Pachacamac, acusando que se llevaba a cabo de manera empírica (Tello 1938, 13 de septiembre: 3 ).

Por su parte, Pedro Villar Córdova (1938, 21 de septiembre: 4), miembro propuesto del referido comité, brindó una entrevista al diario El Comercio del 21 septiembre, donde planteó que las labores de limpieza fueron 
necesarias y no afectaban los contextos funerarios del santuario e hizo hincapié en la urgencia de contar con un camino que impidiera los daños realizados por los visitantes al santuario arqueológico.

De acuerdo con los documentos descritos metodológica y técnicamente en esta intervención se identificaron las siguientes labores: ejecución de los registros gráficos y fotográficos antes, durante y después, para lo cual se contó con la participación del fotógrafo Abraham Guillén y el pintor Sabino Springett, quien realizó el dibujo en detalle de los murales, al que años más tarde se le denominaría el "Facsímil de Pachacamac", actualmente en el Museo de Arqueología y Antropología (Marcone 2003). Ese registro representa uno de los más detallados de pinturas murales complejas, de gran magnitud, a escala real elaborados con el empleo de las artes plásticas (Mallma 2015) (Figuras 7 y 8).

Así, las labores de intervención se concretaron a: limpieza o descombramiento de material de colapso y deposiciones eólicas que cubrían el monumento; seguido del completamiento de muros mediante la reutilización e integración de materiales del monumento y, finalmente, consolidación y protección de la pinturas murales con resinas sintéticas y colocación de una mampara de madera con vidrios sobre los murales mejor conservados (Figuras 9,10 y 11). Cabe mencionar que no se ha podido definir qué resina se empleó, si el Ambroid recomendado por Richards o el Alvar sugerido por Kidder.
Sobre la conservación de pinturas murales para el caso mexicano, Orea (2010) manifiesta que durante los años veinte y treinta del siglo $x x$ se utilizaron materiales modernos para la restauración de monumentos arqueológicos e históricos con pintura mural, como el cemento para su fijado y consolidación, lo que produjo trágicos resultados. Agrega, además, que esa actividad fue realizada por arquitectos, arqueólogos y antropólogos en un escenario donde no se definían criterios de intervención ni se tenía en cuenta el uso de materiales específicos para cada caso así como tampoco para los procesos de alteración posteriores sobre el bien intervenido.

Al respecto, si bien corresponden a ese periodo en cuestión, en el Perú se carece de información sobre conservación de monumentos arqueológicos y, principalmente,

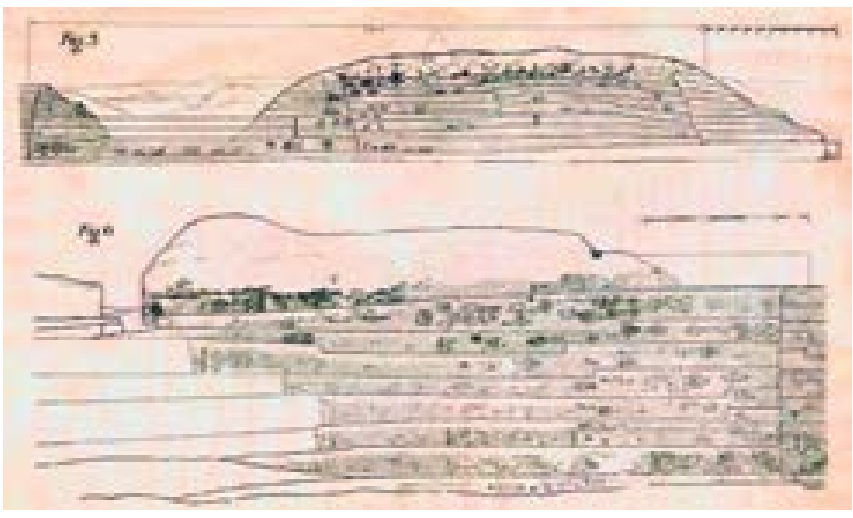

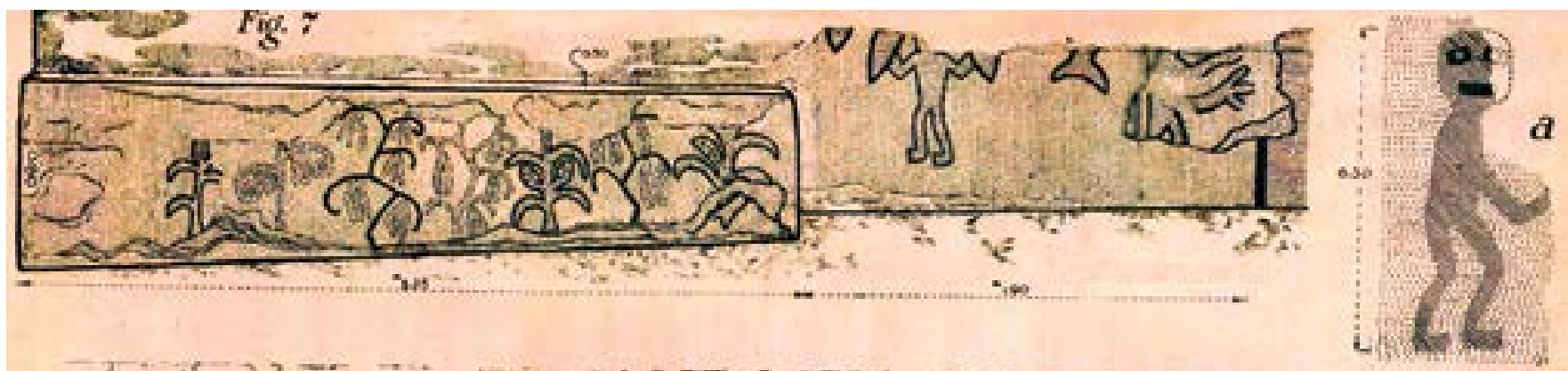

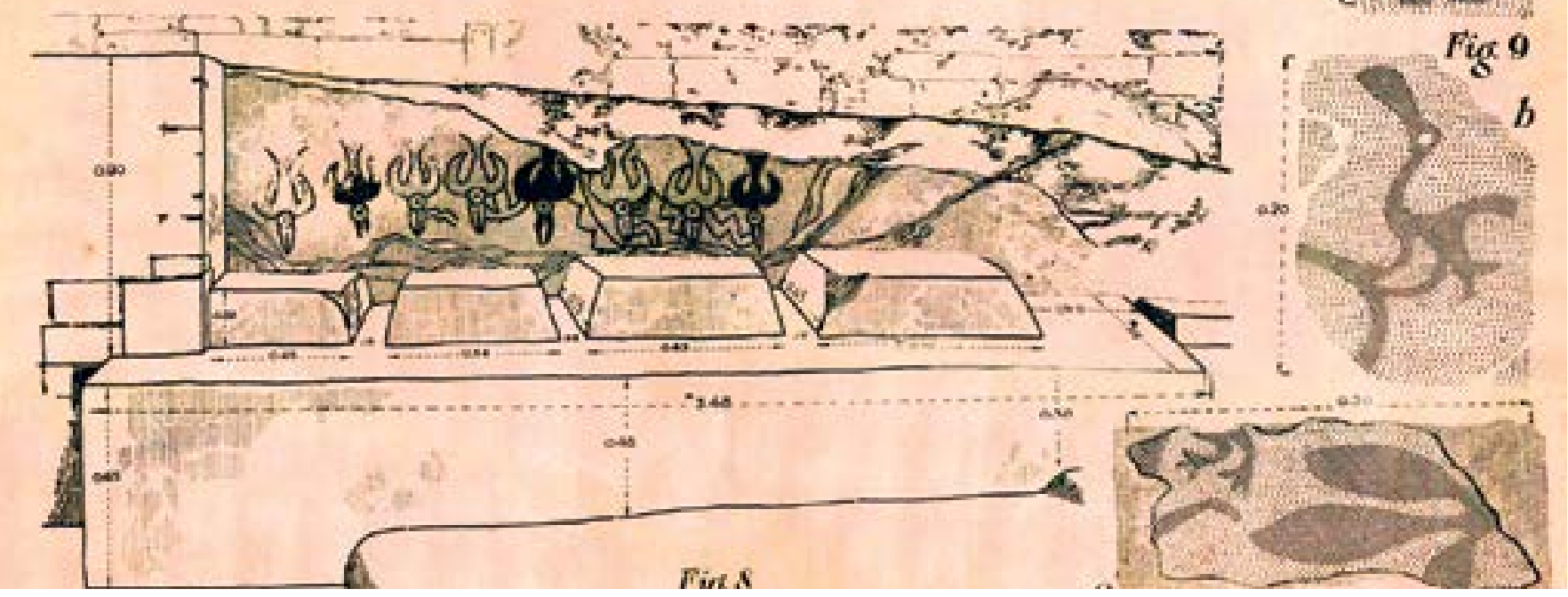

FIGURAS 7 y 8 . Detalle de los dibujos en el frontis norte del Templo Pintado, elaborado por Sabino Springett (Fuente: Muelle y Wells 1939: Figuras 5 y 6). 


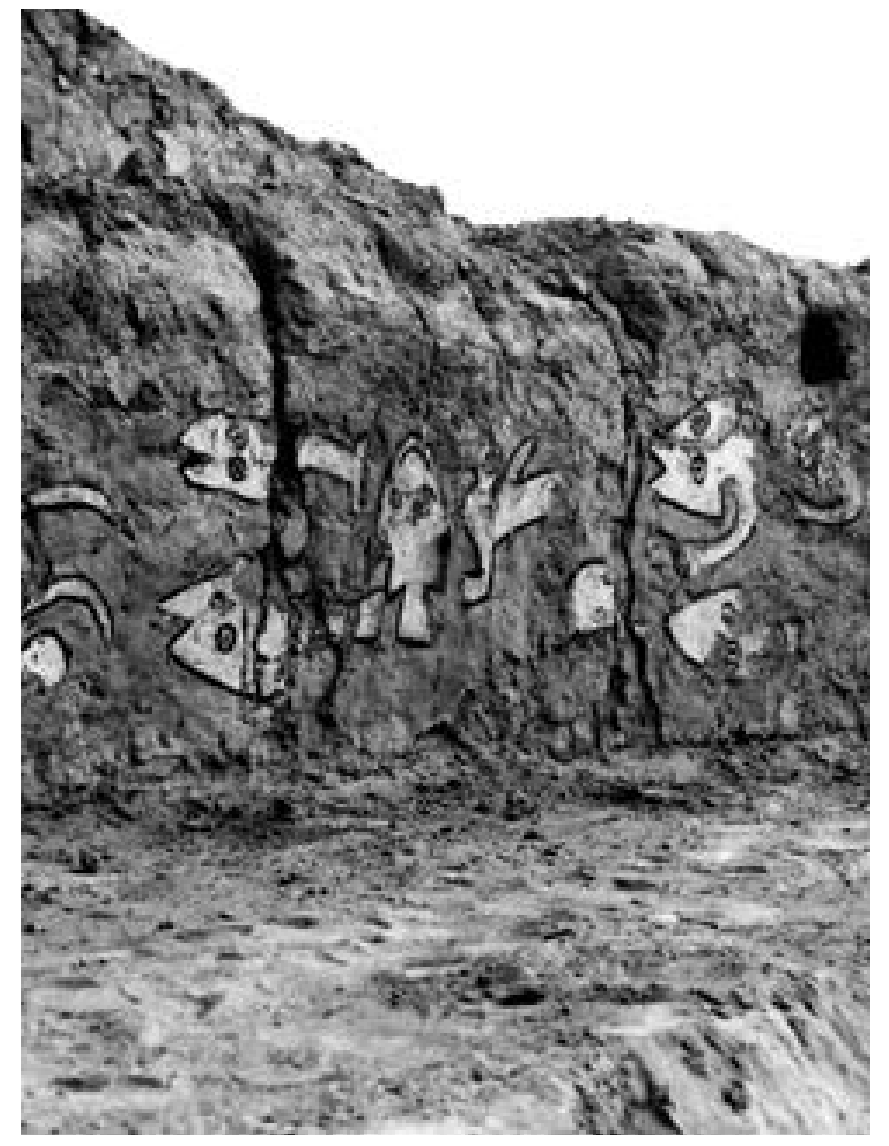

FIGURA 9. Detalle de la pinturas murales antes de su intervención (Fuente: Pozzi-Escot 2018: 290-291). de pinturas murales. A nivel general, Hayakawa (2001) caracteriza la conservación de bienes ya sea arqueológicos o históricos como un proceso donde la actuación de los interventores es de tipo empírico y academicista, con una inexistente especialización en la conservación, basado en el "gran conocimiento de la tecnología artesanal y de los estilos y órdenes pero sin conciencia histórica de sus intervenciones" (Hayakawa 2001: 569).

El uso recurrente de resinas sintéticas o polímeros para la conservación de pinturas murales se dio en México en la década de 1970 (Orea 2010), como parte de un proceso de aplicación de recetas experimentales procedentes de Europa y sin ahondar en sus procesos físicos y químicos

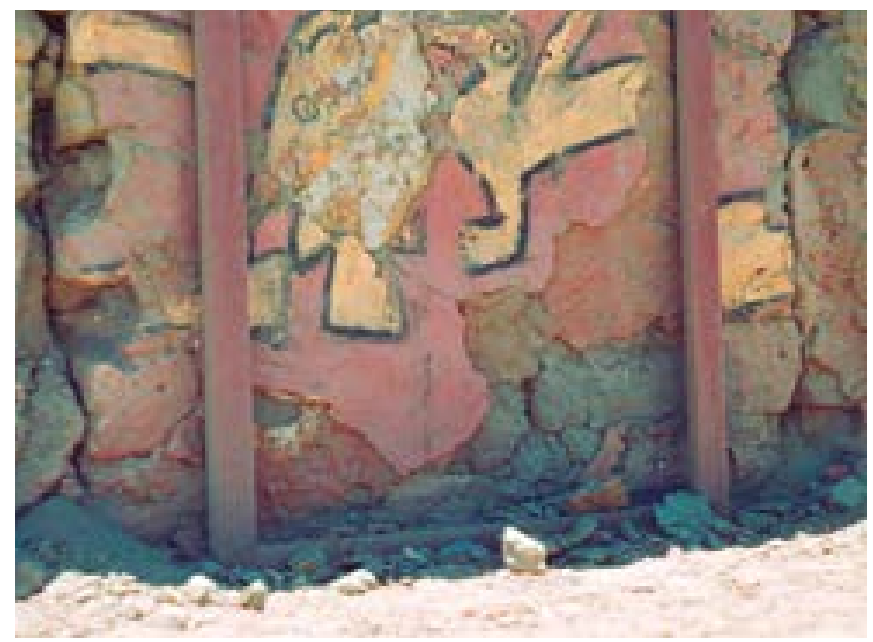

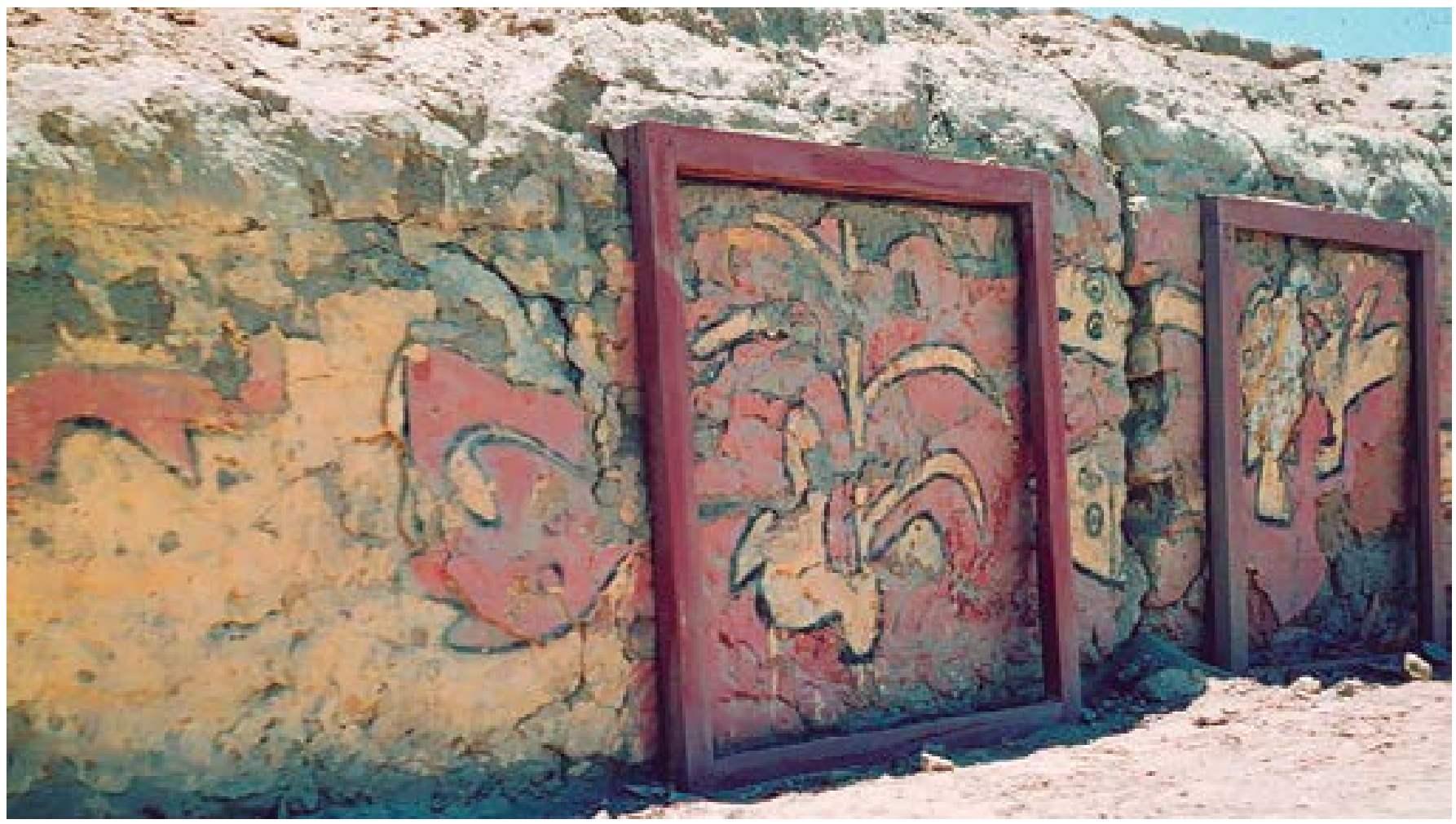

FIGURAS 10 y 11. Situación de las mamparas de vidrio deterioradas en 1940, según imágenes de los archivos de Paul Hanna (Fuente: Pozzi-Escot et al. 2013: 27) 
de alteración luego de la intervención. Decenios después, se identificó que, tras el empleo de esas resinas, ante la presencia de la humedad constante, aparecieron sales solubles, desplazamiento de minerales, hidrólisis de carbonatos, contracción-expansión de arcillas, lo que en conjunto ocasionó la pérdida o alteración de los materiales constitutivos (García et al. 2010). De acuerdo con la temporalidad del empleo de las resinas sintéticas en el Templo Pintado 1938, éstas se usaron decenios antes de su uso masivo en otras latitudes.

En tercer lugar, finalmente, desde el punto de vista de la gestión, dotar de un circuito de visitas al santuario marcaba una novedosa etapa de socializar el bien arqueológico en la población en general y en el turismo en particular, pues ofrecería condiciones adecuadas para su visita. Albert Giesecke, al concluir la tarea encomendada, elaboró un informe al ministro de Relaciones Exteriores en el que recomendó continuar la conservación de Pachacamac mediante un trabajo formal y de largo plazo. Sugirió, asimismo, que se publicaran los resultados y hallazgos de su intervención en un número especial de la revista del Museo Nacional de Lima (Rubio Correa 2007). En 1939, se publicaría la investigación de Jorge Muelle y Robert Wells, quienes focalizaron sus estudios sólo en los detalles de los diseños de los murales del Templo Pintado y los materiales de elaboración, mas no en las actividades realizadas por Giesecke.

\section{Conclusiones preliminares y perspectiva de estudios}

A manera de conclusión preliminar, por lo hasta aquí descrito se expondría lo siguiente:

- La documentación inédita del Archivo Giesecke brinda información — que se creía inexistente- sobre los inicios de la conservación en el Santuario de Pachacamac, del Templo Pintado y, en general, de los monumentos arqueológicos en el Perú, y destaca el papel fundamental que realizó desde el punto de vista político, teórico, metodológico-técnico y de gestión del monumento.

- La conservación del Templo Pintado —uno de los primeros casos de intervención de este tipo en monumentos arqueológicos en el Perú- expone la aplicación de las resinas sintéticas para la consolidación de la pintura mural como parte del empleo de materiales modernos para su preservación.

- La conservación del Santuario de Pachacamac y otros monumentos, como Cajamarquilla y Chan Chan, surgió como parte de la política del gobierno peruano en la realización de un acto internacional, pues involucró la participación de profesionales e instituciones del ámbito público y privado.
Como perspectiva de estudio se expone lo siguiente:

- Realizar una comparación crítica entre los procedimientos ejecutados en el Templo Pintado por Albert Giesecke con los principios rectores de la Carta de Atenas de 1931, con el fin de identificar su reconocimiento, aceptación y aplicación para la intervención del patrimonio arqueológico.

- Llevar a cabo estudios multidisciplinarios sobre propiedades físicas y químicas en el Templo Pintado, los que permitirían identificar las resinas sintéticas empleadas en la pintura mural así como sus procesos patológicos decenios después, de tal manera que sea posible reformular metas y tareas pendientes o confirmar los procedimientos realizados en la actualidad en dicho monumento.

- Sistematizar la información que brindan los documentos del archivo Giesecke sobre la conservación de los demás monumentos del santuario, como el Templo del Sol, el Acllawasi y el circuito de visitas, con lo que se tendría una visión general de la intervención de Albert Giesecke y de sus consecuencias.

- Investigar y analizar el escenario político, ideológico y normativo de los gobiernos en turno en los que se llevó a cabo la intervención de Pachacamac e identificar si ésta fue una actuación programática o consecuencia de discursos políticos de cada época.

- Identificar casuísticas de intervenciones similares en otras latitudes de América Latina para casos de monumentos arqueológicos, con la finalidad de reconocer el accionar de diversos profesionales e instituciones en pro de la conservación y protección de patrimonio.

\section{Agradecimientos}

A mis amigos: la arquitecta Mirna Soto Medina, por sus críticos comentarios a la primera versión del escrito, y al arqueólogo Jorge Montenegro Cabrejos, por su paciente y crítica lectura del manuscrito y traducción de los documentos del Archivo Giesecke, cuyos aportes fueron fundamentales para la presentación del presente artículo.

\section{Referencias}

Arcila, José

2009 "La Declaración Americana y los Derechos de los Familiares de la Víctima", American University International Law Review 25 (1): 145-174.

Asencios, Gerbert

2018 "La restauración del Acllawasi en el Santuario de Pachacamac, 1940-1944. Identificando las huellas de Violletle-Duc, un análisis comparativo", Devenir. Revista de Estudios sobre Patrimonio Edificado 4 (7): 29-48. 
Astuhuamán, César y Richard E. Daggett

2005 "Julio César Tello Rojas: arqueólogo. Una biografía", En Julio C. Tello (comp.), Paracas. Primera parte, Lima, Universidad Nacional Mayor de San Marcos, SISBIB, pp. 17-61.

Bennett, Wendell

1938 [Carta para Albert Giesecke (trad. J. Montenegro)], Archivo Albert Giesecke (Folder AG-0117), IRA, PUCP, Lima, 20 de septiembre.

García, Claudia, Valeria García, y Adela Vásquez

2010 "Soluciones integrales a la problemática de conservación de los acabados arquitectónicos de Mayapán, Yucatán", Intervención 1 (2): 49-55, DOI: 10.30763/Intervencion.2010.2.23.

Giesecke, Albert

ca.1938 Archivo Albert Giesecke-Documentos (Folder: AGD-194; AG-D-195; AG-D-0221; AG-D-1261), Instituto Riva Agüero, Pontificia Universidad Católica del Perú, Lima.

1938a [Carta para Wendell Bennet (trad. J. Montenegro)], Archivo Albert Giesecke (Folder AG-0117)], IRA, PUCP, Lima, 14 de septiembre.

1938b Las ruinas de Pachacamac serán restauradas con fines turísticos. La Prensa, Lima, 14 de septiembre: 3.

1938 [Carta para Alfred Kidder (trad. J. Montenegro)], Archivo Albert Giesecke (Folder AG-0833), IRA, PUCP, Lima, 20 de septiembre.

1938 [Carta para Pedro Villar Córdova], Archivo Albert Giesecke (Folder AG-1809) IRA, PUCP, Lima, 14 de octubre.

1938 [Carta para Paul Richards (trad. J. Montenegro)], Archivo Albert Giesecke (Folder AG-1261), IRA, PUCP, Lima, 17 de octubre.

1938c [Carta para Santiago Antúnez de Mayolo], Archivo Albert Giesecke (Folder AG-1810) IRA, PUCP, Lima, 21 de octubre.

1938d [Carta para Luis E. Valcárcel], Archivo Albert Giesecke (Folder AG-1807) IRA, PUCP, Lima, 21 de octubre.

Hayakawa, José

2001 "Pasos y contrapasos. Marco sistémico para la comprensión del proceso histórico de la restauración de monumentos en la provincia de Lima", tesis de de Arquitectura, Lima, Universidad Nacional de Ingeniería.

Kidder, Alfred

1938 [Carta para Albert Giesecke (trad. J. Montenegro)], Archivo Albert Giesecke (Folder AG-0833), IRA, PUCP, Lima, 20 de septiembre.

Mallma, Karla

2015 "Sabino Springett y su labor como artista plástico", cap. I, en Instituto de Investigaciones en Arte Peruano (ed.), Sabino Springett. Su trayectoria como muralista, ilustrador gráfico y dibujante arqueológico, Lima, Universidad Peruana de Ciencias Aplicadas, pp. 17-74.

Marcone, Gianccarlo

2003 "Los murales del Templo Pintado o relación entre el Santuario de Pachacamac y la iconografía tardía de la costa central peruana", Anales del Museo de América 11: 57-80.
Matos Mar, José, José Deustua y José Luis Rénique

1981 Luis E. Valcárcel. Memorias, Lima, Instituto de Estudios Peruanos.

Matsumoto, Go.

2005 "Pachacamac gis Project: A Practical Application of Geographic Information Systems and Remote Sensing Techniques in Andean Archaeology", tesis de maestría, documento electrónico disponible en [https://www.researchgate.net/ publication/257028267_Pachacamac_GIS_Project_A_Practical_Application_of_Geographic_Information_Systems_and_ Remote_Sensing_Techniques_in_Andean_Archaeology], consultado en noviembre de 2018.

Ministerio de Cultura

2015 Manual de intervención arqueológica de Chan Chan, Trujillo, Ministerio de Cultura-Proyecto Especial Complejo Arqueológico Chan Chan.

Muelle, José, y Richard Wells

1939 "Las pinturas del templo de Pachacámac", Revista del Museo Nacional (8): 265-282.

Orea, Haydeé 2010 "El proceso de formación de corrientes y criterios propios de la conservación de la pintura mural en México", Crónicas 14: 188-198.

Pacheco, Gianella

2014 "Conservación de las estructuras y murales del Templo Pintado de Pachacamac", En Pozzi-Escot (comp.), Pachacamac: conservación en arquitectura en tierra, Lima, Ministerio de Cultura, pp. 143-163.

Pozzi-Escot, Denise

2018 Pachacamac. El oráculo en el horizonte marino del sol poniente, Lima, Banco de Crédito del Perú.

Pozzi-Escot, Denise; Gianella Pacheco y Carmen R. Uceda 2013 Pachacamac: Templo Pintado. Conservación e investigación, Lima, Ministerio de Cultura.

Richards, Paul

1938 [Carta para Albert Giesecke (trad. J. Montenegro)], Archivo Albert Giesecke (Folder AG-1261), IRA, PUCP, Lima, 27 de septiembre.

Rubio Correa, Marcial

2007 Albert Anthony Giesecke Parthymueller, El más peruano de los norteamericanos, Lima, Nova Print.

Schavelzon, Daniel

1990 La conservación del patrimonio cultural en América Latina: restauración de edificios prehispánicos en Mesoamérica: 1750 - 1980, Buenos Aires, Instituto de Arte Americano.

Sotelo, Áureo 1987 Santiago Antúnez de Mayolo, Lima, Editorial Monterrico (Serie Los que hicieron el Perú).

Tello, Julio C.

1938 "Las excavaciones que se efectúan en Pachacamac". El Comercio, Lima, 13 de septiembre: 3.

2010 Cuadernos de investigación del Archivo Tello N 10. Arqueología e Historia de Pachacamac, Lima, Museo de Arqueología y Antropología Universidad Nacional Mayor de San Marcos, Cepredim-UNMSM. 
Villalta Vizcarra, Ana E.

2007 "La contribución de América al derecho internacional", en Organización de Estados Americanos, XXXIII Curso de Derecho Internacional, Rio de Janeiro, OEA, pp. 59-94.

Villar Córdova, Pedro

1938 Las excavaciones en Pachacamac y la arquitectura religiosa de los valles de Lima, El Comercio, 21 de septiembre: 4. Willey, Gordon R.

1967 Alfred Vincent Kidder 1885-1963, Washington, National Academy of Science, documento electrónico disponible en [http://www.nasonline.org/publications/biographical-memoirs/memoir-pdfs/kidder-alfred.pdf], consultado en noviembre de 2018.

\section{Ficha curricular del/los autor/es}

\section{Gerbert Asencios Lindo}

Facultad de Arquitectura Urbanismo y Artes,

Universidad Nacional de Ingeniería (UNI), Perú

gerbert.asencios@gmail.com

Licenciado en arqueología (Universidad Nacional Mayor de San Marcos [UNMSM], Perú) y candidato a maestro en ciencias (Universidad Nacional de Ingeniería [UNI], Perú); estudioso, en el campo arqueológico, de los procesos constructivos relacionados con el empleo de las shicras y sitios fortificados en los andes centrales. Sus líneas de investigación son la metodología y el registro de lesiones y procesos patológicos de arquitectura en tierra, así como la historia de la conservación en el Perú, principalmente, de los monumentos arqueológicos prehispánicos. 